\section{Evaluation of fast growing tree water use under different soil moisture regimes using wick lysimeters}

\author{
Dario Mantovani $^{(1-2)}$, Maik Veste ${ }^{(3)}$, Annika Badorreck ${ }^{(2)}$, Dirk Freese ${ }^{(2)}$
}

The cultivation of fast growing trees has high potential for bioenergy production on marginal lands. Information about the water use efficiency in combination with the ecophysiological response to drought stress is still incomplete. For the study of the transpiration-biomass relations satisfactory results can be obtained under controlled conditions by using lysimeters. Nonetheless, several technical problems related to the manufacturing can bias the outcome. Pan lysimeters are economical and relatively easy to assemble, however, saturation at the lower boundary can happen. On the other hand tension lysimeters, where the suction is applied by a vacuum pump, are effective but expensive and need constant maintenance. To avoid stagnancy and reduce production costs we assembled a tension controlled wick lysimeter, where the tension at the bottom layer is actively exerted by a hanging water column through the wick material (rockwool). We aim to assess the performance of the wick lysimeter coupled with an automatic irrigation system for the study of water useyield relation black locust (Robinia pseudoacacia L.) under different irrigation regimes. The volumetric soil content for each treatment, namely low water (LW), medium water (MW) and high water amount $(\mathrm{HW})$, was maintained at $0.07,0.14$ and $0.2 \mathrm{~m}^{3} \mathrm{~m}^{-3}$ respectively. During the vegetation period (161 days) the plants growing at LW reduced their water use by $60 \%$, their leaf area by $40 \%$ and the total above ground biomass by $46 \%$. As a result, we found a linear correlation $\left(R^{2}=0.98\right)$ between the relative biomass produced and the relative water use. The calculated relative water use efficiency (RWUE) for black locust total above ground dry biomass is 0.96 . Furthermore, after the harvest we evaluated the effectiveness of the lysimeter and irrigation system: the soil moisture of the treatments was kept up at the predefined values and an unsaturated condition at the boundary layer was maintained throughout the vegetation period. Because of the improved design no roots grew into the drainage extension and no unexpected change of the lysimeters hydraulic property occurred. Considering the relatively low-cost material used and the low maintenance needed, compared to other tension controlled lysimeters, wick lysimeters are effective tools for forestry studies of young trees.

Keywords: Black Locust, Soil Moisture Dynamic, Unsaturated Conditions, Hydrostatic State, Wilting Point, Relative Water Use Efficiency

\section{Introduction}

Production of renewable energy in line with the $\mathrm{CO}_{2}$ emission and fossil fuel reduction policy over the last decades has been strongly promoted worldwide. Among different possible sources of raw material for bioenergy production, short-rotation plantations can be a valuable choice for marginal land where conventional agriculture is not effective (Gupta \& Mohan 1982). In our work we investigated the tree species black locust (Robinia pseudoacacia L.), widely used for short-rotation forestry and agroforestry systems for biomass production in East Germany and Hungary (Tsakov \& Alexandrov 2005, Böhm et al. 2009, Rédei \& Veperdi 2009, Grünewald et al. 2009, Veste et al. 2013). Despite the fact that black lo- cust has the potential to become an important tree species for short-rotation plantation in Central and Eastern Europe, the work done in relation to its water use efficiency (WUE) is rare. In our studies the response of the atmospheric evaporative demand, in terms of water use and biomass production, is investigated at whole plant level. Since the biomass production depends directly on the climatic conditions and soil water availability (Sinclair et al. 2005), the study of the intertwined relation between soil moisture, microclimatic boundary conditions and growth response is crucial (Oliver et al. 2009), particularly in terms of biomass production and water consumption in relation to photosynthesis and $\mathrm{CO}_{2}$ uptake regulated by black locust to the soil water availability and
(1) Brandenburg University of Technology, International Graduate School, Konrad-Wachsmann-Allee 6, D-03046 Cottbus (Germany); (2) Brandenburg University of Technology, Chair of Soil Protection and Recultivation, KonradWachsmann-Allee 6, D-03046 Cottbus (Germany); (3) Centre for Energy Technology Brandenburg e.V., FriedliebRunge-Str. 3, D-03046 Cottbus (Germany)

@ Dario Mantovani (mantdar2@gmail.com) Received: May 04, 2012 - Accepted: Feb 11, 2013

Citation: Mantovani D, Veste M, Badorreck A, Freese D, 2013. Evaluation of fast growing tree water use under different soil moisture regimes using wick lysimeters. iForest 6: 190-200 [online 2013-05-08] URL: http://www.sisef.it/iforest/contents/? id=ifor0100-006

Communicated by: Roberto Tognetti

the stomata (Rodríguez-Iturbe \& Porporato 2004). Hence the knowledge of the water use (Kutílek \& Nielsen 1994) is a key issue for understanding the processes between soil and plant, especially on marginal lands (Lindroth \& Bath 1999, Böhm et al. 2011), where the water availability is often erratic. In order to minimize the numerous variables involved, the experiment is carried out under semi-controlled conditions by using lysimeters. In addition, to reduce the complexity of the comparison with other case studies, due to the inhomogeneity of the methodology (Stanhill 1986, Monteith 1993, Byrd \& May 2000) and the experimental conditions, the water use efficiency in our investigation is expressed in relative terms (RWUE). The construction of the lysimeters involves several technical issues that could seriously bias the results of the experiment (Lewis \& Sjöstrom 2010); however, satisfactory outcomes for agronomic and forestry investigation have been achieved (Ritchie \& Burnett 1968, Williams et al. 2003, Müller \& Bolte 2009). There is a wide set of solutions for lysimeter and monitoring systems (Derby et al. 2002, Evett et al. 2009, Beeson 2011), which are tightly related to the scope of the investigation and the project funding. As a consequence, dimension, localization, time scale and maintenance costs of the lysimeters are essential factors to be taken into account. Zero-tension lysimeters are relatively economical, easy to build, and need low maintenance, which allows the user to increase the number of replicas. However, stagnancy at the bottom layer can occur (Abdou \& Flury 2004 ) with the consequence of anaerobiosis conditions at root level (Klocke et al. 1993), 
which can affect the ecophysiological response of the trees. That risk can only be minimized with the construction of relatively deep lysimeters, where no roots are growing at the bottom layer. Otherwise, water accumulation at the bottom layer can be prevented by using a tension controlled lysimeter, in which the tension is actively exerted by porous plates, cups or candles connected to a vacuum pump. Nonetheless, the costs of the systems are rather elevated, and therefore their use is often limited by the budget of the investigation. They further require high technical maintenance; in addition the pumps need power supply, which is a supplementary impediment, when the installation is in secluded areas. An acceptable compromise between the two extremes of lysimeter typology is the tension controlled wick lysimeter (Weihermüller et al. 2007), where the stagnancy is avoided by constant suction performed by a hanging water column through the wick material (Holder et al. 1991, BenGal \& Shani 2002). The improved drainage efficiency of the wick lysimeter against the zero-tension lysimeter has already been described in a critical comparison (Zhu et al. 2002, Mantovani et al. 2011). Because of their relatively low-cost construction material, easy installation and independence from power supplies, wick lysimeters are particularly suitable for remote sites and allow the increase of numbers of replicas. Our wick lysimeters are coupled with an automatic drip-irrigation system and a wireless data acquisition system, which allow controlling and monitoring the soil moisture dynamics and water supply via internet connections. The aim of the experiment is to test the performance of the newly developed wick lysimeter for the evaluation of biomass-water use relation of young trees. More in detail we verify: (a) the effectiveness of the wick material on maintaining a constant unsaturated condition at the bottom layer; (b) that unwanted changes of the wick lysimeter hydraulic property due to a translocation do occur; (c) the efficiency of the new automatic irrigation system in maintaining the soil moisture at predefined values; and (d) the suitability of the novel application for stopping roots growing into the wick material. For all the duration of the investigation, the lysimeter has fulfilled our expectations. The link between water availability and the biomass investigated and all other results are satisfactory. The hydraulic properties of the lysimeters have been verified after the experiment, and no unpredicted changes have occurred. The soil water content of the different treatments has been maintained at the predefined values and no stagnancy at the lower boundary happened, for all the duration of the experiment.

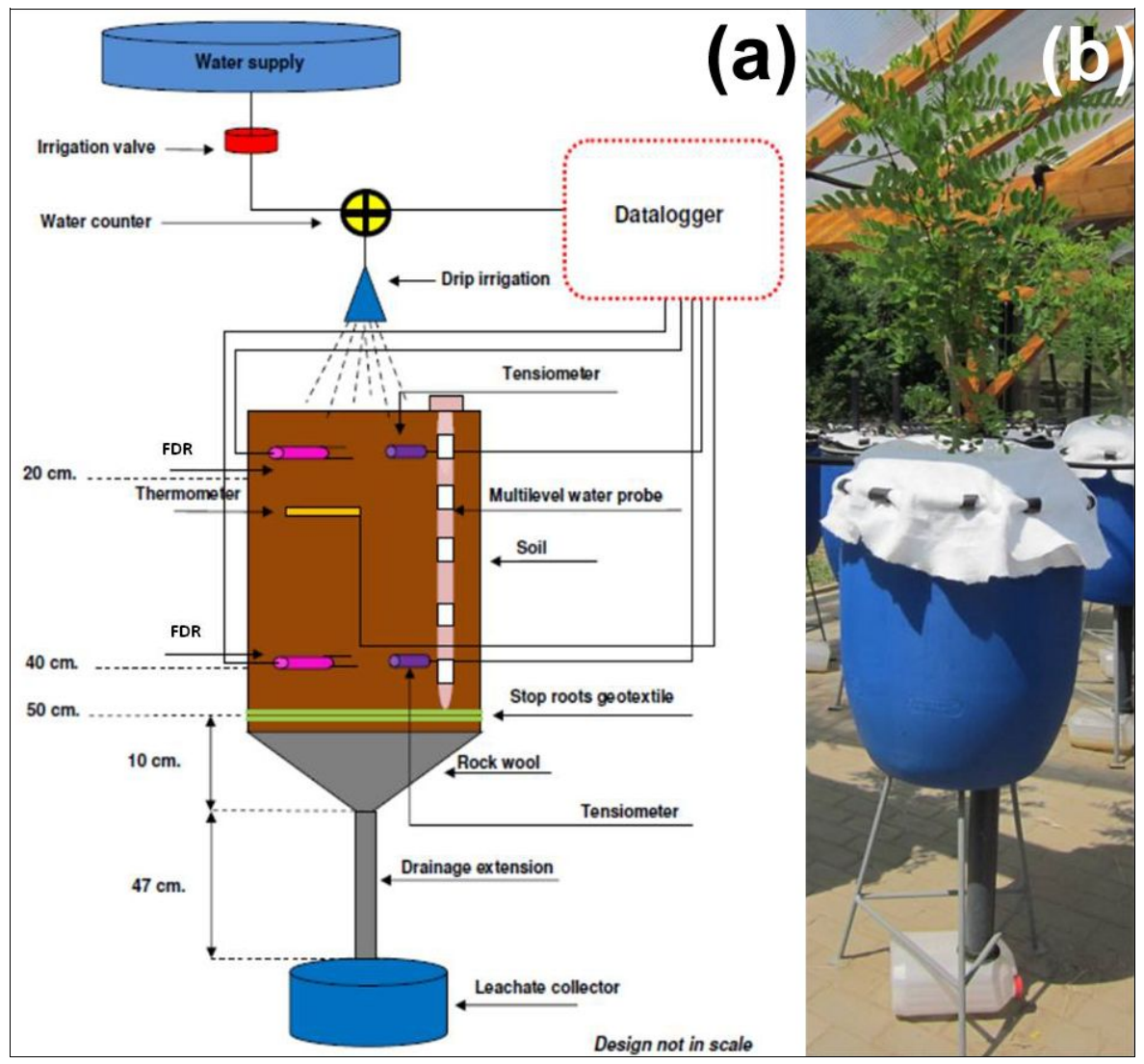

Fig. 1 - Schematic diagram (a) and overview (b) of the wick lysimeter and automatic irriga tion system.

\section{Material and methods}

\section{Plant material}

Two-year-old black locust trees (Robinia pseudoacacia L.) were collected from a short rotation coppice in the re-cultivated post-mining area in Welzow-Süd $(20 \mathrm{~km}$ south of Cottbus, Brandenburg, Germany) in November 2010. Before digging out the trees, the main branches were cut back at approx. $10 \mathrm{~cm}$ from the trunk. The plants were established into $15 \mathrm{~L}$ plastic pots, and settled in a protected area during the winter to avoid damages from frost. In March 2011 the plants were transplanted into the wick lysimeters and fertilized with $1045 \mathrm{ml}$ of Hoagland standard solution and $3.18 \mathrm{~g}$ (equivalent to $40 \mathrm{~kg} \mathrm{ha}^{-1}$ ) of monopotassium phosphate $\left(\mathrm{KH}_{2} \mathrm{PO}_{4}\right)$. To facilitate a successful establishment of the trees, the plants were maintained at well-watered conditions for two months before starting water treatments.

\section{Biomass measurements}

At the end of the experiment the new branches and the leaves were harvested separately and oven-dried at $65{ }^{\circ} \mathrm{C}$ until a constant dry weight. To quantify the water limitation effects the values of the soil moisture, the total above-ground biomass production, the total leaf area, and the water use efficiency are expressed in relative terms, considering the maximum mean value equal to one and referring all the other values to it. The relative total above-ground biomass production was calculated by adding the estimated values of the trunk mass increment to the harvested biomass. The relative total leaf area was estimated at the harvest, multiplying the total leaf weight for the weight-area index $\left(\mathrm{kg} \mathrm{m}^{-2}\right)$, obtained from representative samples $(n=80)$. The relative water use efficiency (RWUE) of the trees was calculated by the ratio between the mean of the relative total above-ground dry biomass produced and the mean of the relative cumulative water used during the vegetation period. In order to test the differences between the variables, a non-parametric Mann-Whitney U-test (two independent samples) was applied.

\section{Lysimeters}

The wick lysimeter was filled at bulk density mean of $1.3 \mathrm{~kg} \mathrm{~m}^{-3}$ with homogenized sandy loam soil, relatively low in carbon and nitrogen content, namely 1.33 and $0.08 \mathrm{~kg}$ $\mathrm{kg}^{-1}$ respectively, previously sieved with a $2000 \mu \mathrm{m}$ mechanic sieve. For the construction of the chambers we used standard polyethylene drums of $50 \mathrm{~cm}$ diameter and $70 \mathrm{~cm}$ height (Fig. 1). To facilitate the drainage, the bottom was funnel-shaped with gravel and adapted for the connection with the highly conductive drainage extension, which exerted constant suction at the lower boundary. The drainage extension consisted of a $6.5 \mathrm{x}$ 
$47 \mathrm{~cm}$ rigid polyethylene pipe filled with rockwool (Sonoroll 035, Deutsche Rockwool, Gladbeck, Germany), with a density of $0.18 \mathrm{~kg} \mathrm{~m}^{-3}$. The extension drainage dimension and the rockwool density were selected in relation to soil type, column dimension, and the hydraulic property of the specific wick material, following the theoretical consideration formulated by Ben-Gal \& Shani (2002). A $5 \mathrm{~cm}$ rockwool layer was befitted between the soil bottom layer and the lysimeter base and connected to the drainage extension (Fig. 2a). To prevent roots from growing into the rockwool a root-stop permeable geotextile (Landschaftsvlies, Delta, Herdecke, Germany) was installed at the soil-rockwool interface (Fig. 2a). At the end of the experiment the lysimeters were emptied and the integrity of the root-stop geotextile and the rockwool were verified. The soil moisture $\left(\mathrm{m}^{3} \mathrm{~m}^{-3}\right)$ and the soil matric potential $(\mathrm{hPa})$ variation was measured on an hourly basis at 20 and $40 \mathrm{~cm}$ depth along the soil profile by FDR sensors (SM-200, Frequency Domain Reflectometry, Soil Moisture Sensor Delta-T Devices, Cambridge, UK) and gypsum tensiometers (SIS, UMS, München, Germany), respectively (Fig. 2b). In order to evaluate the water status of the soil column, for the calculation of the weekly changes in water storage, during the filling process a $2.5 \times 50 \mathrm{~cm}$ fiberglass access tube (Delta-T Devices, Cambridge, UK) was installed into each wick lysimeter It allowed the soil moisture measurement along the soil profile in $10 \mathrm{~cm}$ intervals by the insertion of a portable FDR profile probe (PR2/4w-02, Delta-T Devices, Cambridge, UK). The soil temperature was monitored hourly by a thermistor (SKTS 200, Skye Instruments Ltd, Powys, UK) installed at $20 \mathrm{~cm}$ depth (Fig. 2b). Due to cost cutting reasons, only one lysimeter for each treatment was monitored with the FDR and gypsum tensiometer, whereas the replicas were equipped only with the fiberglass access tubes and monitored weekly. Water was supplied solely by an automatic drip irrigation system, at a rate of $38 \mathrm{~mm} \mathrm{~h}^{-1}$, and its amount depended on the differences between the actual soil moisture measured by the FDR sensor installed at $20 \mathrm{~cm}$ depth and the predefined value. To avoid uncontrolled water input, the wick lysimeter system was installed under a light transmissive roof. The daily applied water volume $(\mathrm{mm})$ was measured by an electronic flow meter and recorded. Leachate was collected from the drainage extension into polyethylene tanks and measured. The evaporation was minimized to nearly zero by covering the soil with a double layer of turf. Microclimatic parameters were measured and recorded on an hourly basis as follows: air temperature and relative humidity were measured by a thermistor-hygrometer ( $\mathrm{HC} 2$ S, Rotronic AG, Bassersdorf, Germany), photosynthetically active radiation by a PAR sensor (QS2, Delta-T Devices, Cambridge, UK) and wind speed by a switching anemometer (A100R, Vector Instruments, Rhyl, UK). All the data collected from the wick lysimeter sensors and from the meteorological station were stored on data loggers (GP1, Delta-T Devices, Cambridge, UK). All data was transferred with a GSM wireless data transmission to an internet platform (WEBVis, Umweltanalystische Produkte $\mathrm{GmbH}$, Cottbus, Germany).

\section{Water treatments}

The experimental design consists of three treatments with three replicates. The different treatments, namely low water amount (LW), medium water amount (MW), and high water amount (HW), were maintained at soil moisture mean of $0.07,0.14$, and 0.2 $\mathrm{m}^{3} \mathrm{~m}^{-3}$ during the experiment from June $1^{\text {st }}$ to November $8^{\text {th }}, 2011$. The upper limit $\left(0.2 \mathrm{~m}^{3}\right.$ $\mathrm{m}^{-3}$ ) corresponds to the hydrostatic state of the soil column in the wick lysimeter, therefore the plants developed without water limitation $(\mathrm{pF} \geq-2)$. The lower limit $\left(0.7 \mathrm{~m}^{3}\right.$ $\mathrm{m}^{-3}$ ) was close to the wilting point value of the plants $(\mathrm{pF} \leq-3.5)$. A dry packing refilling of the lysimeters was chosen in order to avoid heterogeneity and preferential flows (Oliveira et al. 1996). In the columns a discrete quantity of soil was damped every $5 \mathrm{~cm}$ and successively packed with a $1 \mathrm{~kg}$ wooden pestle. After filling the wick lysimeters to further the particle settling, the soil columns were subjected to wetting-drying cycles over a period of one month before planting. To monitor a possible translocation of the smaller soil particles $(<63 \mu \mathrm{m})$ and colloids (Warrington et al. 2007) through the soil profile, as a consequence of intensive irrigation, the particle size distribution (PSD) was evaluated before the experiments and after the vegetation period. We chose three granulometric classes, namely medium sand (2000-200 $\mu \mathrm{m})$, fine sand $(200-63 \mu \mathrm{m})$ and a sum of silty and clay fraction $(<63 \mu \mathrm{m})$. In order to maintain the colloids within the fine particles category $(<63 \mu \mathrm{m})$, no pre-treatment $\left(\mathrm{H}_{2} \mathrm{O}_{2}\right.$ and $\mathrm{HCL}$ for the destruction of the organic carbon and carbonates respectively) was applied to the soil, but pyrophosphate dispergation. We made use of the wet sieving method, utilizing a set of sieves with mash of $200 \mu \mathrm{m}$ and $63 \mu \mathrm{m}$. The particles retained in the set of sieves, and the mixture obtained was oven-dried at $105{ }^{\circ} \mathrm{C}$, till a steady state was reached, and then they were weighed. To detect a possible a translocation effect, we compared the silt and clay fraction at different depths before and after the experiment with the Mann-Whitney U-Test, since the normality test failed. The saturated hydraulic conductivity was determined in undisturbed soil cores $\left(100 \mathrm{~cm}^{3}\right)$ taken from three lysimeters at the depths of 5, 20 and 40

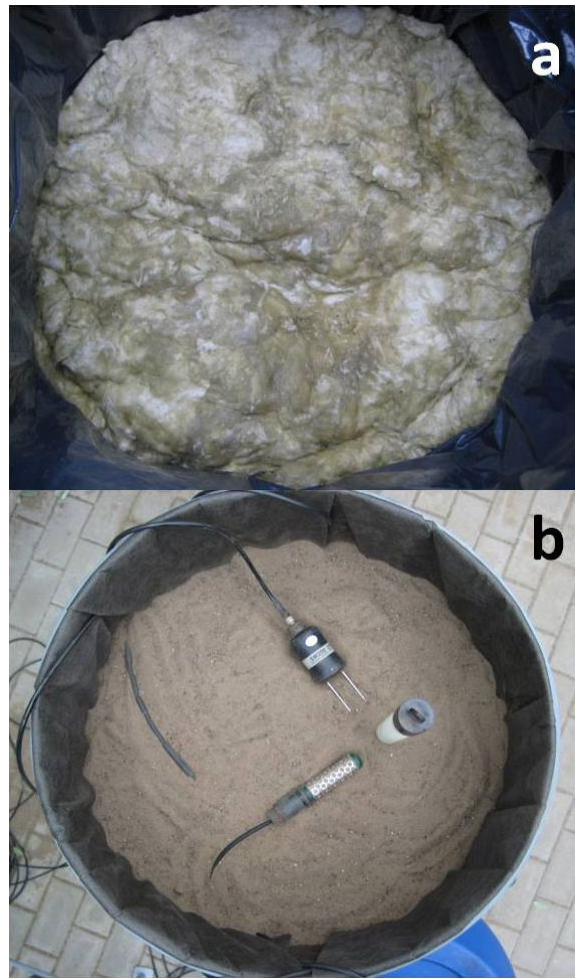

Fig. 2 - (a) Rockwool installation at the lysimeter bottom; and (b) FDR, tensiometer, and thermistor sensors in the lysimeter.

$\mathrm{cm}$ in four replicates. We chose the permanent-head method using a lab permeameter (Eijkelkamp, Giesbeek, Netherlands). After measuring the bulk density of the same cores was determined by drying them at $105^{\circ} \mathrm{C}$ till a steady state. The water retention curve of a soil type describes the relation of volumetric soil moisture and matric potential at steady state conditions. For the indirect method, we used four undisturbed soil samples $\left(100 \mathrm{~cm}^{3}\right)$ from three lysimeters at three depths $(5,20$ and $40 \mathrm{~cm}$ ). The cores were saturated and subsequently equilibrated at increasing matric potentials in steps from 10 to $300 \mathrm{hPa}$, using ceramic plates. The samples were weighed at every step to determine the volumetric water content. The van Genuchten equation (van Genuchten 1980) was fitted to the data in order to derive a continuous curve. To enhance the accuracy of the FDRprobes we conducted the standard calibration procedure according to the manual (SM200, Delta-T Devices, Cambridge, UK), using twelve undisturbed soil samples taken from the lysimeters at three depths (20 and $40 \mathrm{~cm}$ ), and equilibrated them to three moisture levels $\left(0.09,0.15\right.$, and $\left.0.28 \mathrm{~m}^{3} \mathrm{~m}^{-3}\right)$. The sensor signal from the samples was corrected according to the actual volumetric water content by modifying the underlying conversion equation. The procedure accounted for both sensor and soil specific inaccuracies. Sensor calibration processes involve some degree of disturbance in the soil column, 


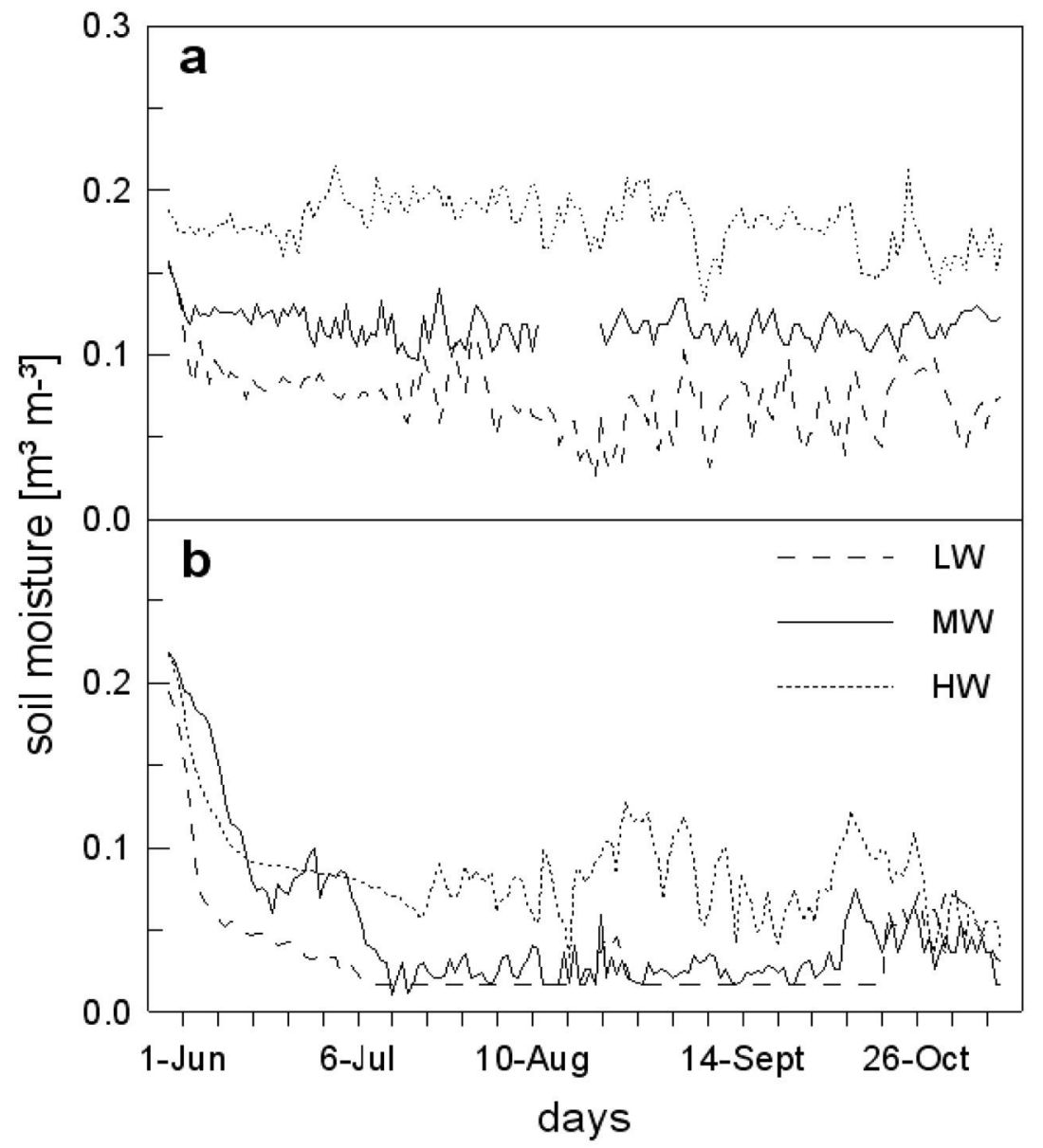

Fig. 3 - Mean daily soil moisture in the lysimeters for low (LW), medium (MW) and high water (HW) amount, measured at $20 \mathrm{~cm}$ (panel a) and $40 \mathrm{~cm}$ (panel b) depth during the experiment from June $1^{\text {st }}$ to November $8^{\text {th }}, 2011$.

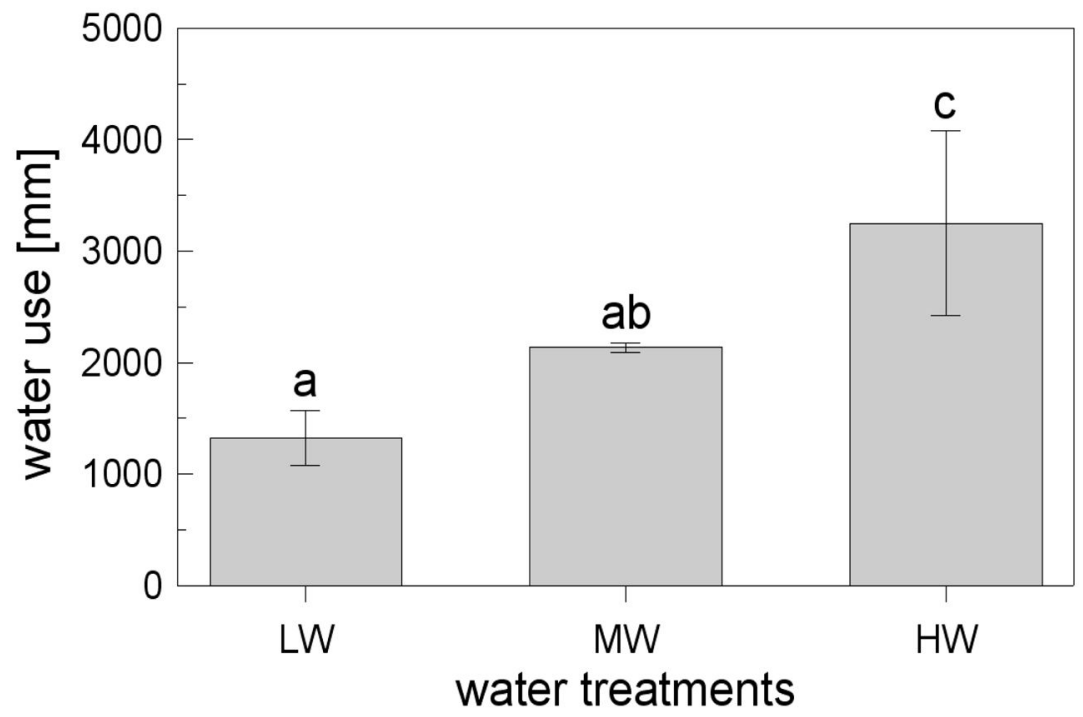

Fig. 4 - Mean and standard deviation of the cumulative water use in relation to the relative soil water availability measured during the experiment from June 1st to November 8th, 2011. Treatments labeled with the same letter are not significantly different $(\mathrm{p} \leq 0.05)$, after nonparametric Mann-Whitney U-test (two independent samples). which were avoided by carrying out the experiment in relative terms, and define the absolute values only at the end of the experiment, after the sensor calibration. For the gypsum tensiometers instead, the calibration resulted more complicated because of the relatively long period of time before the sensor reaches the equilibrium with the surrounding soil and for its inaccuracy. Consequently we used the water retention curve ( $\mathrm{pF}$ curve) obtained with the indirect method to link the matric potential values at any given soil moisture.

\section{Water balance}

The weekly water use was obtained from the terms of the experimental water balance after eqn. 1 :

$$
T=I-E-L e-\Delta S
$$

where $T$ is the tree transpiration, $I$ the irrigation, $E$ the evaporation, $L e$ the leachate, and $\Delta S$ the water storage variation. Evaporation from the lysimeters was minimized, covering the soil surface with fleece, thus $E$ can be set to 0 in eqn. 1 .

\section{Results}

\section{Plants}

During the growing season, the soil moisture of the three different treatments was maintained within the preconceived values of $0.07,0.14$, and $0.2 \mathrm{~m}^{3} \mathrm{~m}^{-3}$, by irrigating the plants only when the soil moisture value was below the fixed limits (Fig. 3). As a response to the water limitation, the LW plants reduced their transpiration rate by $60 \%$, in comparison to the HW plants. The mean cumulative water used $(\mathrm{mm})$ for each treatment during the vegetation period is shown in Fig. 4 , where the water used during the growing season is related to the relative soil water availability. The plants in the different treatments used the water at different rates during the vegetation period. In Fig. 5 the three phases of the growth are displayed (Tab. 1): (i) beginning from June $1^{\text {st }}$ to July $6^{\text {th }}$, where for all the treatments the rate was under 10 $\mathrm{mm}$ day $^{-1}$; (ii) the peak from July $6^{\text {th }}$ to September $15^{\text {th }}$, where all the plants reached the maximum rate; and (iii) the decline phase, characterized by a decrease of the rate, till reaching the minimum at the end of the vegetation period (from September $15^{\text {th }}$ to November $8^{\text {th }}$ ). During the peak period, the LW plants reduced the transpiration significantly, by $42 \%$ and $61 \%$ as compared to the MW and HW, respectively. Conversely, no differences between the treatments were found at the beginning and the decline periods. Water limitation caused the reduction of the transpiring surface and the biomass production. At the end of the growing period the total leaf area of the LW plants was re- 
Fig. 5 - Means and standard deviation of te water use measured during the vegetation period from June $1^{\text {st }}$ to November $8^{\text {th }}$, 2011. (a): High water amount $(\mathrm{HW})$; (b): medium water amount (MW); (c): low water amount (LW).

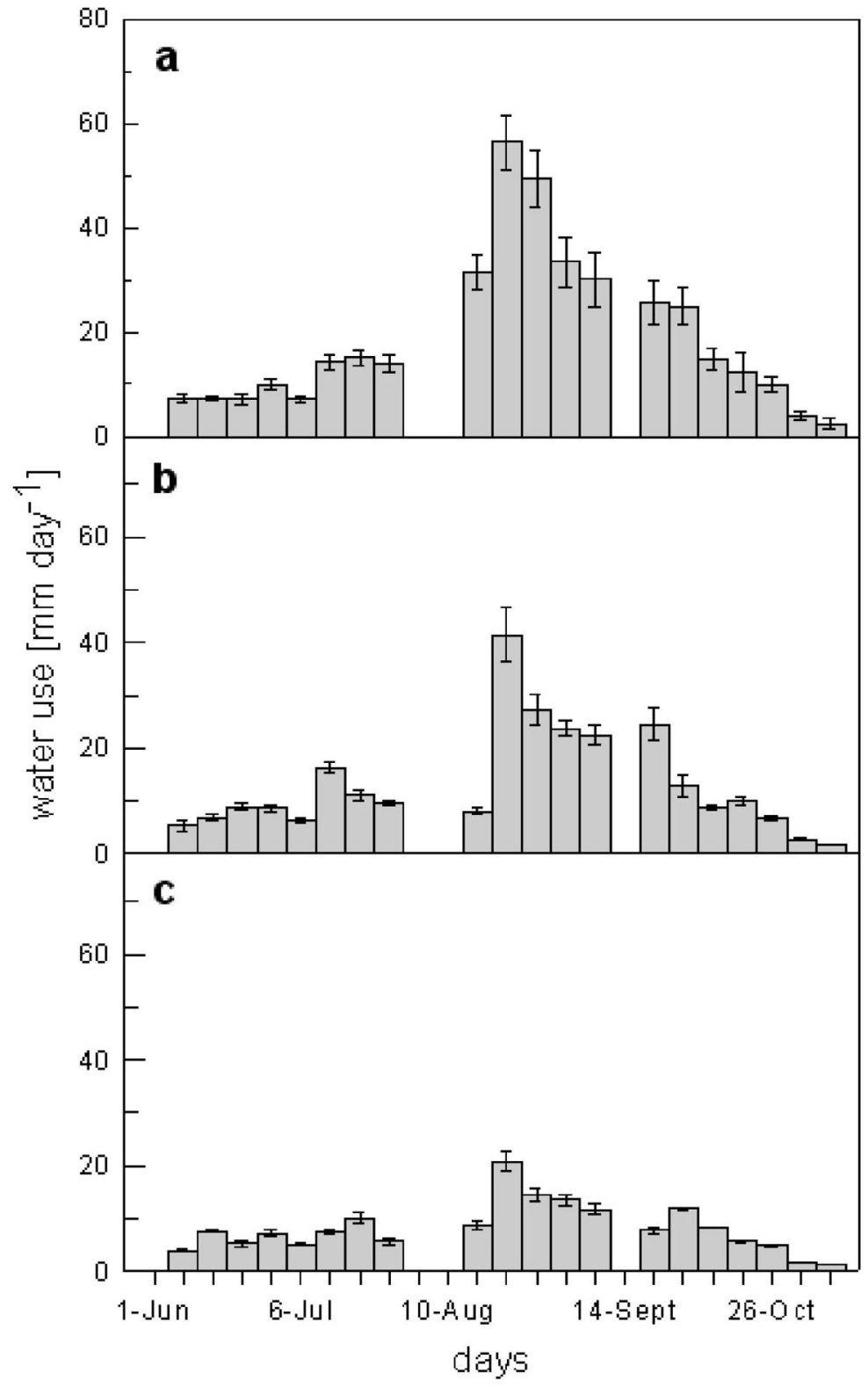

duced by $30 \%$ and $60 \%$, compared to the MW and HW, respectively (Fig. 6a). The LW biomass production instead was reduced by $4 \%$ and $53 \%$ compared to the MW and HW treatments, respectively (Fig. 6b). We could calculate a linear relation $\left(\mathrm{R}^{2}=0.98\right)$ between the above ground biomass and the water use (Fig. 7). The calculated relative water use efficiency (RWUE) for black locust total above ground dry biomass evaluated at the harvest was 0.96 , and the difference between the treatments is not statistically significant.

\section{Lysimeter performance}

Even with a certain degree of fluctuation, due to the faster soil moisture dynamics, the method was effective for the differentiation of the treatments (Fig. 4) when compared to a system without boundary. Soil moisture dynamics for all the treatments are shown in Fig. 3. After the initial stage of abundant irrigation, which facilitated the plant establishment and where the soil moisture value at both depths was $>0.15 \mathrm{~m}^{3} \mathrm{~m}^{-3}(\mathrm{pF} \geq-2)$, we distinguished a reduction of the soil moisture also at the bottom layer. As expected from the hydraulic characteristics of the lysimeter,

Tab. 1 - Transpiration rate means in relation to the different periods of the growing season (from June $1^{\text {st }}$ to November $8^{\text {th }}$ ). $\left({ }^{*}\right)$ : Across the period of the vegetation season, numbers labeled with the same letters are not significantly different $(\mathrm{p} \leq 0.05)$ after non-parametric Mann-Whitney U-test (two independent samples). Within the period vegetation season: numbers labeled with the same symbol are not significantly different $(\mathrm{p} \leq 0.05)$.

\begin{tabular}{lcccccc}
\hline \multicolumn{1}{c}{ Period } & $\begin{array}{c}* \mathbf{L W} \text { mean } \\
\left(\mathbf{m m ~ d a y}^{-1}\right)\end{array}$ & $\begin{array}{c}\text { Std } \\
\left(\mathbf{m m ~ d a y}^{-1}\right)\end{array}$ & $\begin{array}{c}* \mathbf{M W} \text { mean } \\
\left(\mathbf{m m} \text { day }^{-1}\right)\end{array}$ & $\begin{array}{c}\text { Std } \\
\left(\mathbf{m m ~ d a y}^{-1}\right)\end{array}$ & $\begin{array}{c}* \mathbf{H W} \text { mean } \\
\left(\mathbf{m m} \text { day }^{-1}\right)\end{array}$ & $\begin{array}{c}\text { Std } \\
\left(\mathbf{m m ~ d a y}^{-1}\right)\end{array}$ \\
\hline beginning & $5.91 \mathrm{a}$ & 1.56 & $7.23 \mathrm{a}$ & 1.54 & $7.79 \mathrm{a}$ & 1.21 \\
peak & $\diamond 10.98 \mathrm{~b}$ & 4.25 & $18.77 \mathrm{~b}$ & 10.29 & $\bullet 28.16 \mathrm{~b}$ & 14.35 \\
decline & $3.43 \mathrm{c}$ & 2.19 & $5.34 \mathrm{a}$ & 3.79 & $8.69 \mathrm{a}$ & 5.36 \\
\hline
\end{tabular}




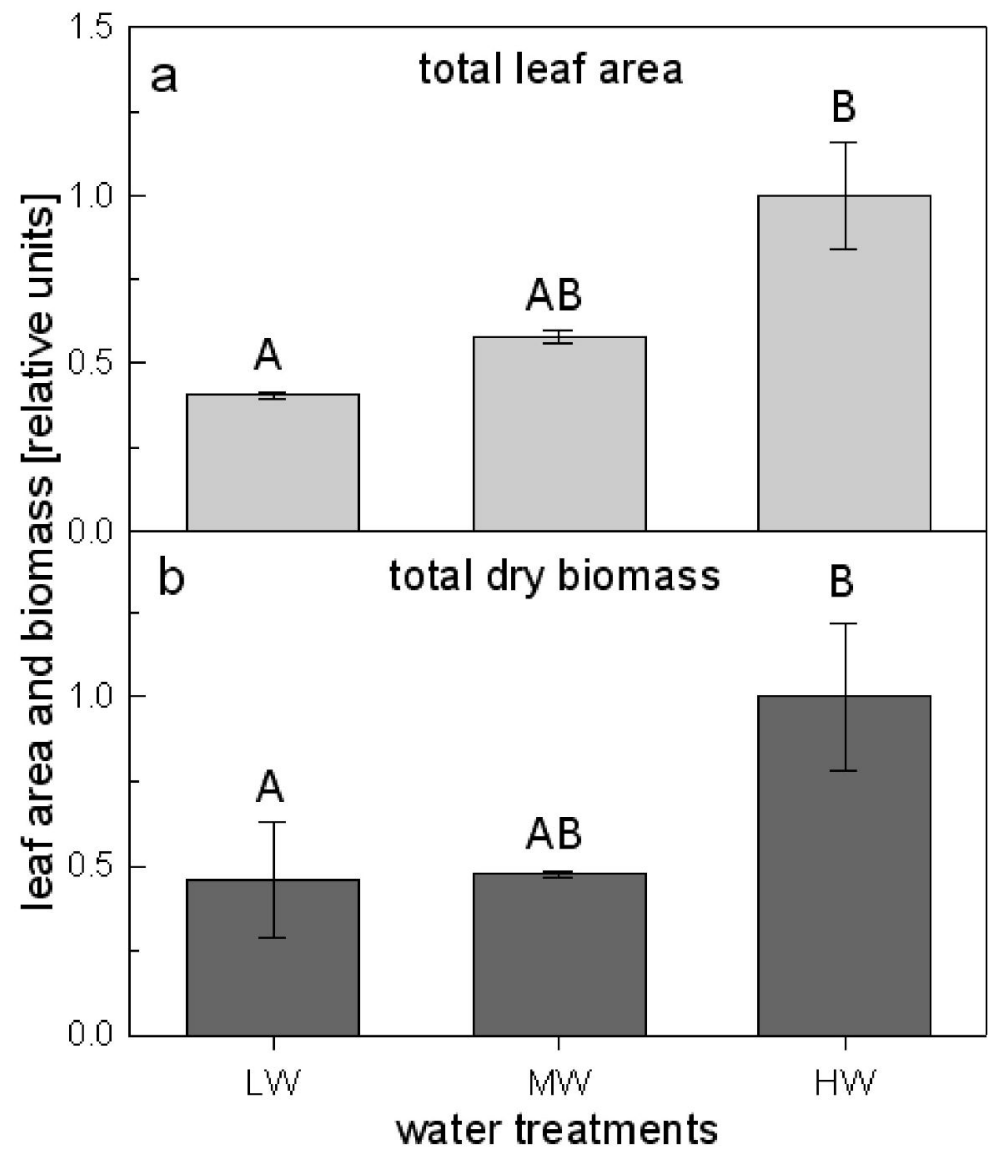

Fig. 6 - Means and standard deviations of the relative (a) leaf area and (b) total above ground dry biomass measured at the harvest (November $8^{\text {th }}, 2011$ ). Treatments labeled with the same letter are not significantly different $(p \leq 0.05)$ after non-parametric Mann-Whitney U-test (two independent samples). after the inspection, and no roots were found in the extension drainage. More accurate information with reference to the soil moisture distribution (every $10 \mathrm{~cm}$ ) was obtained by inserting the FDR profile probe periodically into the fiberglass access tube. The trends of the obtained values by the FDR profile probe measured at 20 and $40 \mathrm{~cm}$ depths, matched up with the soil moisture values obtained by the FDR sensors installed at the same depths (20 and $40 \mathrm{~cm}$ ). After the calibration of the sensors and the validation of the data, the FDR profile probe was particularly useful for the evaluation of the storage variation along the soil profile for the weekly water budget estimation (Fig. 8). The total volume of leachate produced decreased from the HW plants (approx. $15 \%$ of the irrigation) to the MW (approx. 2\% of the irrigation), till no leachate at all for the LW. Less effective was the use of the gypsum tensiometers. The information we acquired, linking the soil moisture to the actual soil water availability, was biased. As a result, making use of the direct method for the soil water retention curve determination after Kutílek \& Nielsen (1994) by using FDR sensors coupled with tensiometers, was not possible. The FDR response to the soil moisture variation was faster than the gypsum tensiometer response, and a hysteresis between both sensors was observed, depending on the soil wetting and drying. Consequently, the relation between the soil water availability and the soil moisture was indirectly estimated (Fig. 9). The particle size distribution did not change significantly across the profile after the investigation (Fig. $10)$. We witnessed a redistribution of the particle size, and the variance between the

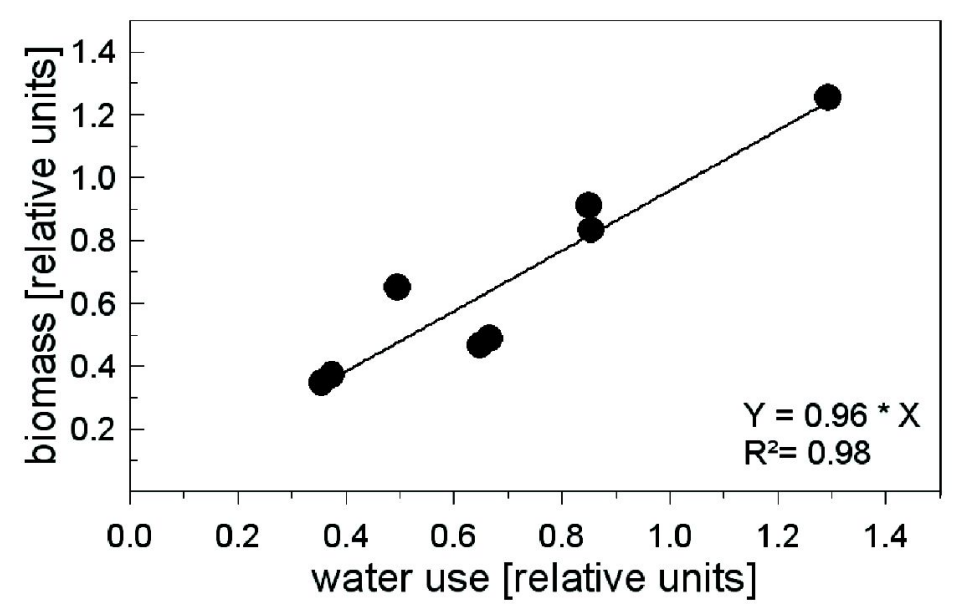

Fig. 7 - Relationship between the mean relative total above biomass production and the mean relative cumulative water used, measured at the harvest (November $8^{\text {th }}, 2011$ ). 
Fig. 8 - Relative weekly experimental water balance for treatments (a) high water amount (HW), (b) medium water amount (MW), (c) low water amount (LW), estimated during the experiment from June $1^{\text {st }}$ to November $11^{\text {th }}$, 2011.

Fig. 9 - Water retention curve fitted with the van Genuchten equation.
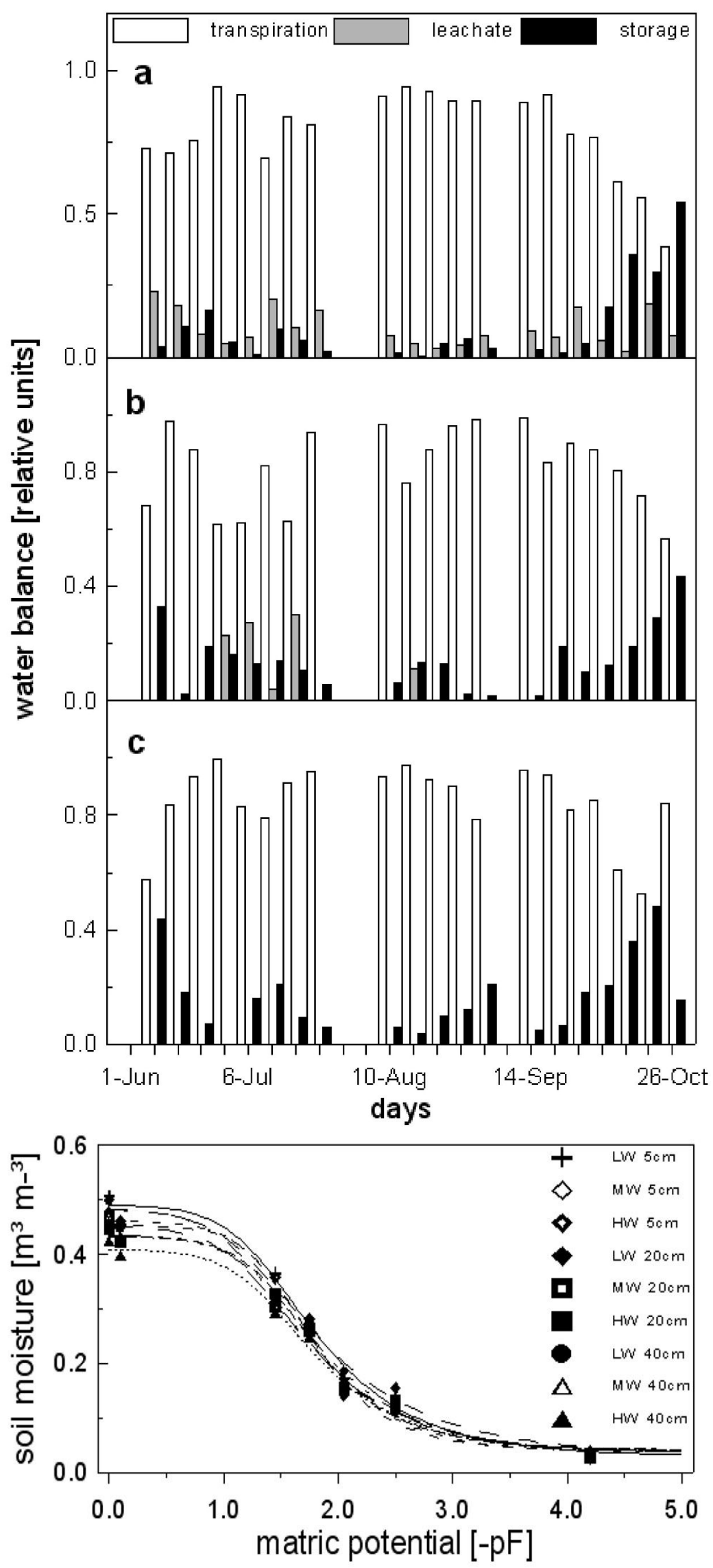
categories was higher, compared to the situation before the experiment. However, by applying the Mann-Whitney U-Test, the difference was not significant. More in detail, enrichment in fine particles, imputable to a translocation, occurred at $20 \mathrm{~cm}$ depth; however, it is not significant (Tab. 2). As expected and verified after the investigation, a settlement of the soil particles occurred resulting in a variation of the saturated hydraulic conductivity $\left(\mathrm{K}_{\mathrm{s}}\right)$ and the bulk density along the soil profile (Fig. 11). The bulk density increased and the $\mathrm{K}_{\mathrm{s}}$ decreased significantly with increasing depth (Tab. 2).
Tab. 2 - Soil properties and silt and clay (including colloids) content mean, measured at different depths $(5,20$, and $40 \mathrm{~cm})$ after the experiment. (*): Parametric ANOVA and post-hoc multiple comparison Tukey HSD test; $(* *)$ : parametric Welch robust test and post-hoc multiple comparison Games-Howell test; (***): non-parametric (two independent samples) Mann-Whitney U test. Numbers labeled with the same letters are not significantly different $(\mathrm{p} \leq 0.05)$.

\begin{tabular}{ccccccc}
\hline $\begin{array}{c}\text { Depths } \\
(\mathbf{c m})\end{array}$ & $\begin{array}{c}\mathbf{K}_{\text {s mean }} * \\
(\mathbf{c m ~ d a y})\end{array}$ & $\begin{array}{c}\text { Std } \\
(\mathbf{c m ~ d a y})\end{array}$ & $\begin{array}{c}\text { Bulk density } \\
\text { mean ** } \\
\left(\mathbf{k g ~ m}^{-3}\right)\end{array}$ & $\begin{array}{c}\text { Std } \\
\left(\mathbf{k g ~ m}^{-3}\right)\end{array}$ & $\begin{array}{c}\text { Silt and clay } \\
\text { mean *** } \\
\left(\mathbf{k g ~ k g}^{-1}\right)\end{array}$ & $\begin{array}{c}\text { std } \\
\left(\mathbf{k g ~ k g}^{-1}\right)\end{array}$ \\
\hline 5 & $1489.9 \mathrm{a}$ & 352.3 & $1.32 \mathrm{a}$ & 0.09 & $13.6 \mathrm{a}$ & 3 \\
20 & $1310.6 \mathrm{a}$ & 284.9 & $1.4 \mathrm{a}$ & 0.05 & $15.3 \mathrm{a}$ & 5.4 \\
40 & $892.4 \mathrm{~b}$ & 240.4 & $1.48 \mathrm{~b}$ & 0.042 & $12.9 \mathrm{a}$ & 3.7 \\
\hline
\end{tabular}

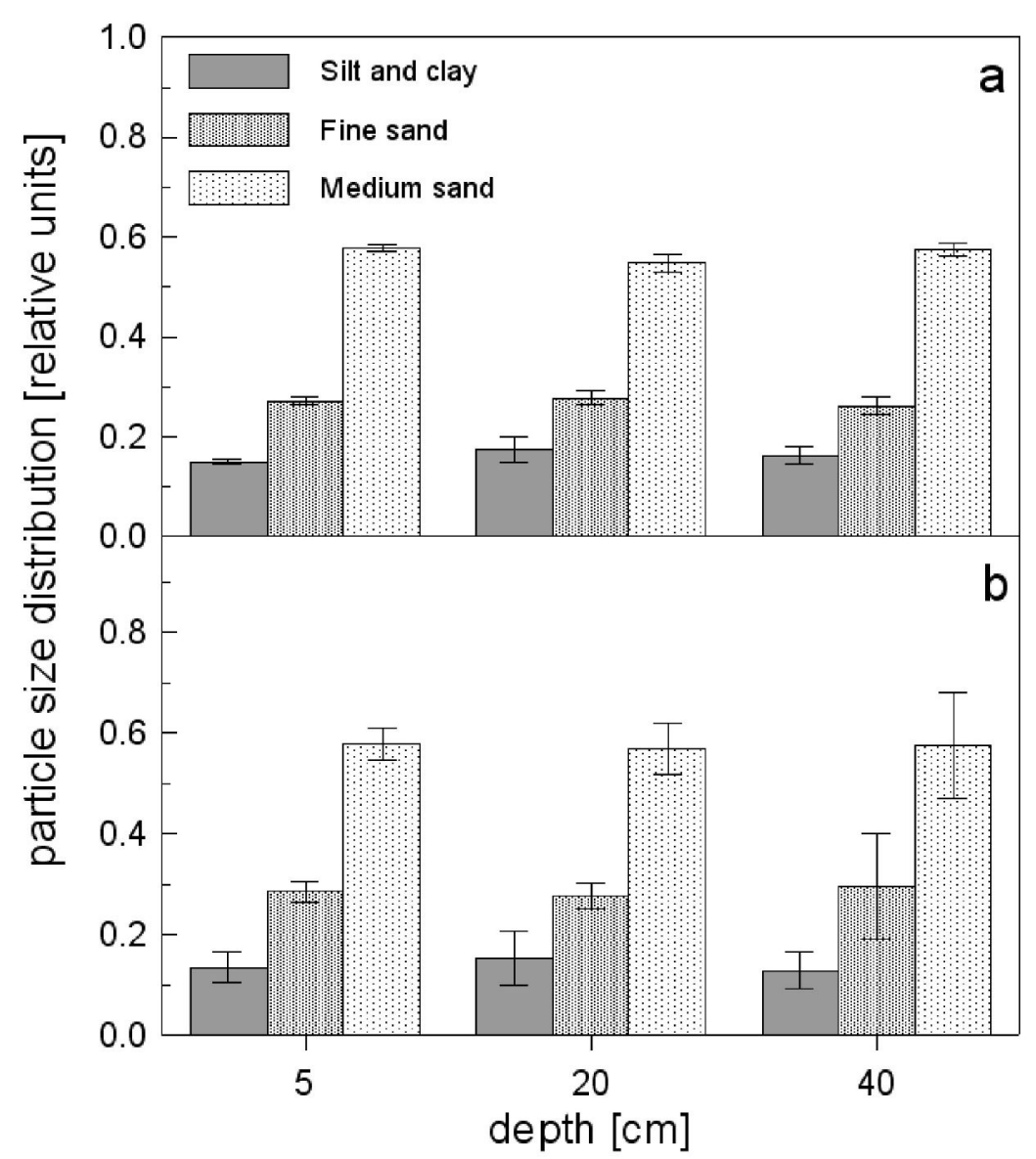

Fig. 10 - Particle size distribution evaluated at 5,20 and $40 \mathrm{~cm}$ depth at the beginning (a) and at the end (b) of the experiment.

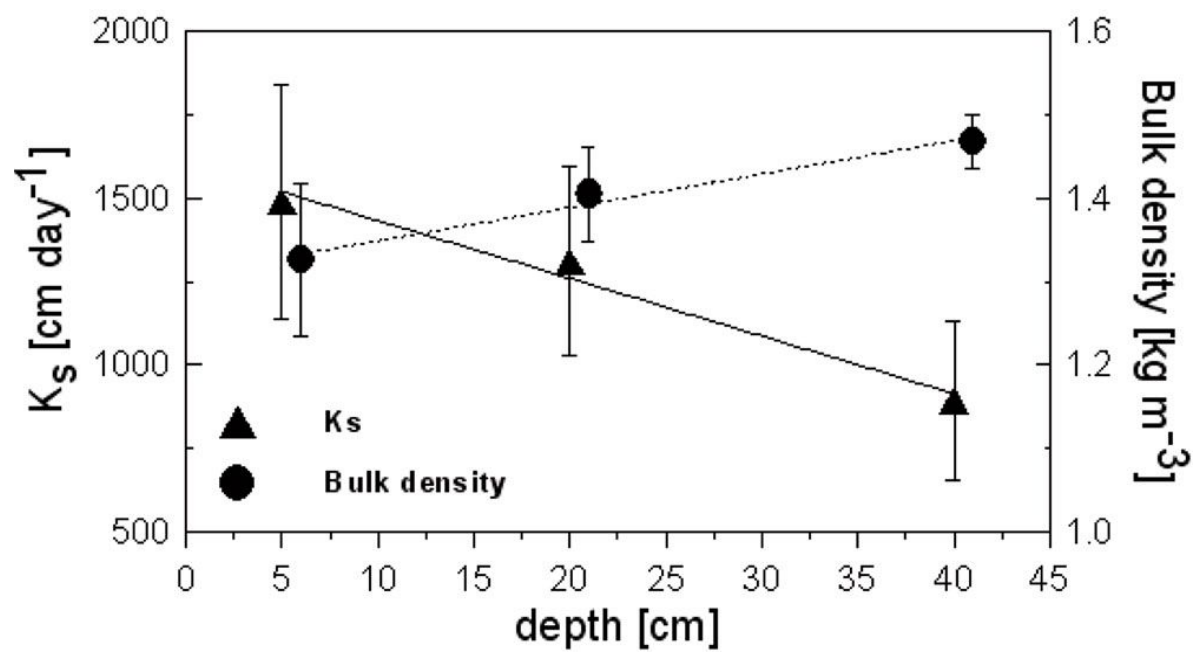

Fig. 11 - Lysimeters saturated hydraulic conductivity and bulk density evaluated at 5,20 and $40 \mathrm{~cm}$ depth at the end of the experiment. 


\section{Discussion}

\section{Plant performance}

The different soil moisture regimes caused the reduction of the LW and MW water use, compared to the HW plants, as a consequence of the ecophysiological adaptation. Stomatal response to soil water availability and atmospheric conditions occurred to minimize the transpirational water loss at leaf level as reported from other studies (Smith \& Griffiths 1993, Nielsen \& Orcutt 1998, Veste \& Kriebitzsch 2013). Furthermore, under constant drought stress the morphological adaptation of the leaves followed and the total leaf area could be reduced by the trees (Veste \& Kriebitzsch 2013). The two dissimilar but inseparable processes can be recognized in details by analyzing Tab. 1 . During the beginning phase, the difference between the treatments in terms of water use was not significant. This occurred because during that phase the dimensions of the plants were comparable, and the minima difference in the water use rate was due mostly to a stomatal regulation. At the peak phase instead, the plants were fully developed and morphological differences could be already observed. The MW and HW plants already had a larger leaf area compared to the ones with drought stress (LW). The differences in the water use rate became significant due to the combined effect of the ecophysiological and morphological adaptation (Veste \& Kriebitzsch 2013). Nevertheless, it is important to mention that during the peak phase the atmospheric evaporative demand was higher compared to the other two phases, therefore also the ecophysiological component was more notable than during the beginning and decline phase. The climatic effect appeared more pronounced during the decline phase. Even though the leaf area across the treatments was statistically different (Fig. 6), the differences between the water use rates across the treatments were not significant, because of the reduced evaporating demand. The prolonged drought stress caused a reduction of the total transpiring area. As a consequence, the biomass production dropped from the HW to the LW plants. The relative water use efficiency (RWUE) for the different treatments is comparable; as a result the relation between the relative water use and the relative biomass production is linear (Fig. 7). It is important to point out that we opted to display the relative results, as data for the comparison of the black locust WUE available in the literature are very scattered and obtained in field experiments, making a direct comparison with our lysimeter studies possible. The WUE values obtained for black locust from field experiments range from $0.03 \mathrm{~kg} \mathrm{~m}^{-3}$ in Georgia, USA (Raper et al. 1992) to $0.74 \mathrm{~kg} \mathrm{~m}^{-3}$ under semi-arid con- ditions on the Loess Plateau in Inner Mongolia (Hu et al. 2001).

\section{Lysimeter performance}

In our lysimeters the experimental water balance was estimated evaluating the variation of the volumetric soil moisture content, by using FDR sensors instead of the typical gravimetric methods by using weighing lysimeters (Jia et al. 2006, Vaughana et al. 2007). The advantage was that the soil moisture content along the soil profile could be monitored continuously. It gave us the option of following the atmospheric evaporative demand by changing the irrigation frequency and volume, and it provided information about the functioning of the lysimeter. With the use of the FDR profile probe we improved the water budget accuracy, by measuring the soil moisture every $10 \mathrm{~cm}$ along the profile. Nonetheless, with the FDR profile probe for the control of the replicas, the costs of the installation were reduced approximately threefold. The correct functioning of the lysimeters and the differentiation of the treatments could be observed by focusing on the leachate and storage changes showed in Fig. 8. The HW treatment produced leachate all the time, ensuring that the plants did not suffer from water limitation (Fig. 8a). With exception of the decline, where transpiration was particularly reduced, we could notice that the soil was constantly close to the hydrostatic state, and the water storage did not change substantially. With the LW treatment instead, no leachate was collected during the vegetation period (Fig. $8 \mathrm{c}$ ). As a consequence, the soil was constantly in a hydrodynamic state and the changes in storage were more pronounced. Summarizing the results of the investigation, we can assess that constant suction was performed by the hanging water column throughout the wick materials, bringing the soil in contact with the wick at a pressure lower than the atmosphere (Gee et al. 2009). Anaerobiosis at the bottom layer, due to soil saturation, did not happen and damages to the root system were prevented. It is crucial to point out that the hydraulic continuity of the lysimeter is an essential requirement for ecophysiological studies, especially for experiments where water stress is induced. An additional complication was to avoid the roots growing into the drainage extension, in which the wick material was wetter than the soil. Strong roots could have damaged the root-stop geo-textile and absorbed the water directly from the wick material, compromising the outcome of the experiment. Due to the irrigation and the natural settlement of the particles, we faced changes in relation to the physical and hydraulic characteristics of the soil column. The increment of the fine particles at $20 \mathrm{~cm}$, even if not significant, could be attributed to a translocation (Pres- ley et al. 2004). The phenomena was not so prominent since, although the irrigation amount was abundant, most of the water was absorbed by the trees and only a relatively small amount $(15 \%$ for $\mathrm{HW}$ and $0 \%$ for $\mathrm{MW}$ and LW) water passed through all the soil profile. As a matter of fact, we did not notice any enrichment in fine particles at $40 \mathrm{~cm}$ depth; (Fig. 10). The significant increase of the bulk density from the top to the bottom (Fig. 11) is due to the isostatic pressure asserted from the upper layers. The increase of the bulk density caused the reduction of the pore total volume and dimension. As a result the saturated hydraulic conductivity decreased. Albeit the performance of the wick lysimeter for forestry research is in line with our expectations, some general considerations related to the use of lysimeters for quantitative and qualitative analysis, must be taken into account:

- the lysimeter volume is generally smaller than the volume of soil used by the roots in natural conditions, therefore the root distribution did not follow the natural patterns;

- the soil column, unless undisturbed, presents physical, chemical and hydrological characteristics that strongly differ from the soil characteristics in the field;

- in a controlled experiment, the natural interaction of the conspecifics and other organisms are minimized, and consequently the plant response is altered.

It has to be remarked that in controlled experiments, the reduction of variables implies the simplification of the natural systems. Hence it is crucial to comprehend that the results achieved are practical for the formulation of assumptions, developing conceptual models, and to clarify the outcome obtained in the field (Karlberg et al. 2006). For a practical use, all the postulations need comparison and validation by using information gathered in field experiments.

\section{Conclusion}

The results achieved by this experiment confirm the relation between the water availability and the biomass production, and stress the importance of the soil-plant-atmosphere interaction analysis in relation to the biomass production. Being expressed in relative terms, the water use efficiency became a useful tool for a preliminary quantitative approach, whenever the issue is the reduction in production due to water shortage. However, it is explicit that the black locust relative water use efficiency is site specific, and a calibration with a database obtained in a field experiment is needed before any further application. The same considerations are also valid for the analysis of the water use rate, which after a site-specific validation of the information related to the phases of growth, can be used for effective forestry practice planning, including irrigation, ferti- 
lization and harvesting schedule. With the use of wick lysimeters, fundamental information could be acquired with a relatively economical system and a minimum of maintenance. The system was able to maintain the soil water content mean values between the established ranges throughout the vegetative period. Unsaturated conditions at the boundary layers were maintained, allowing the adequate plant growth. Furthermore, providing the lysimeters with a wireless data transmission system, they could be installed in secluded places, without the necessity of daily inspection. This aspect is particularly important for agronomic and forestry investigations where the study areas are often located at a longer distance from the user's working place. The relatively low-cost material, easy manufacturing and minimal maintenance make the wick lysimeters suitable for studies where the water distribution along the soil profile and the numbers of replicas is important. Our findings should be considered as an example of the wide range of information attainable and the versatility of the system also for forestry.

\section{Acknowledgements}

We thank Alon Ben-Gal (Agricultural Research Organisation, Gilat, Israel) for his valuable comments on the design of the lysimeters and the two reviewers for valuable comments to improve the manuscript. The research was funded by the International Graduate School of the BTU Cottbus.

\section{References}

Abdou HM, Flury M (2004). Simulation of water flow and solute transport in free-drainage lysimeters and field soils with heterogeneous structure. European Journal of Soil Science 55: 229241. - doi: 10.1046/j.1365-2389.2004.00592.x

Beeson RC (2011). Weighing lysimeter systems for quantifying water use and studies of controlled water stress for crops grown in low bulk density substrates. Agricultural Water Management 98: 967-976. - doi 10.1016/j.agwat.2011.01.005

Ben-Gal A, Shani U (2002). A highly conductive drainage extension to control the lower boundary condition of lysimeters. Plant and Soil 239: 9-17. - doi: 10.1023/A:1014942024573

Byrd GT, May PA (2000). Physiological comparisons of switchgrass cultivars differing in transpiration efficiency. Crop Science 40: 12711277. - doi: 10.2135/cropsci2000.4051271x

Böhm C, Quinkenstein A, Freese D, Hüttl RF (2009). Wachstumsverlauf von vierjährigen Robinien. Allgemeine Forstzeitung - Der Wald 10: $532-533$

Böhm C, Quinkenstein A, Freese D, Hüttl RF (2011). Assessing the short rotation woody biomass production on marginal post-mining areas Journal of Forest Science 57 (7): 303-311.

Derby NE, Knighton RE, Montgomery BR (2002). Construction and performance of large soil core lysimeters. Soil Science Society of America Journal 66: 1446-1453. - doi: 10.2136/ sssaj2002.1446

Evett SR, Mazahrih NT, Jitan MA, Sawalha MH, Colaizzi PD, Ayars JE (2009). Weighing lysimeter for crop water use determination in the Jordan Valley, Jordan. American Society of Agricultural and Biological Engineers 52 (1): 155-169.

Gee GW, Newman BD, Green SR, Meissner R, Rupp H, Zhang ZF, Keller JM, Waugh WJ, Van der Velde M, Salazar J (2009). Passive wick fluxmeters: design considerations and field applications. Water Resources Research 45: 9-17. doi: 10.1029/2008WR007088

Grünewald H, Böhm C, Quinkenstein A. Grundmann P, Eberts J, von Wühlisch G (2009). Robinia pseudoacacia L.: a lesser known tree species for biomass production. BioEnergy Research 2: 123-133. - doi: 10.1007/s12155-0099038-x

Gupta T, Mohan D (1982). Economics of trees versus annual crops on marginal agricultural lands. Oxford \& IBH Publishing Co., New Delhi, India.

Holder M, Brown KW, Thomas JC, Zabcik D, Murray HE (1991). Capillary wick unsaturated pore water sampler. Soil Science Society of America Journal 55: 1195-1202. - doi: 10.2136/ sssaj1991.03615995005500050001x

Hu ZH, Wang ZG, Gao HX, Wang LJ (2001). Research on water changes and water use efficiency in loess gully region in western Shanxi Province. Journal of Shanxi Agricultural University 21 (3): 248-251.

Jia X, Dukes MD, Jacobs JM, Irmak S (2006). Weighing lysimeters for evapotranspiration research in a humid environment. American Society of Agricultural and Biological Engineers 49 (2): 1-12.

Karlberg L, Ben-Gal A, Jansson P-E, Shani U (2006). Modelling transpiration and growth in salinity-stressed tomato under different climatic conditions. Ecological Modelling 190: 15-40. doi: 10.1016/j.ecolmodel.2005.04.015

Klocke NL, Todd RW, Hergert GW, Watts WG, Parkhurst AM (1993). Design, installation, and performance of percolation lysimeters for water quality sampling. Trans. American Society of Agricultural and Biological Engineers 36: 429435.

Kutílek M, Nielsen DR (1994). Soil hydrology. Catena Verlag, Cremlingen, Germany.

Lindroth A, Bath A (1999). Assessment of regional willow coppice yield in Sweden on basis of water availability. Forest Ecology and Management 121: 57-65. - doi: 10.1016/S0378-1127 (98)00556-8

Lewis J, Sjöstrom J (2010). Optimizing the experimental design of unsaturated soil columns. In: Proceedings of the $19^{\text {th }}$ World Congress of Soil Science "Soil Solutions for a Changing World". Brisbane (Australia) 1-6 August 2010.

Mantovani D, Freese D, Veste M, Hüttl RF (2011). Modified wick lysimeters for critical water use efficiency evaluation and yield crop mo- delling. In: Proceeding of the $14^{\text {th }}$ Lysimeter Conference "Lysimeters in Climate Change Research and Water Resources Management". Gumpenstein (Austria) 3-4 May 2011, pp. 245248.

Monteith JL (1993). The exchange of water and carbon by crops in a Mediterranean climate. Irrigation Science 14: 85-91. - doi: 10.1007/ BF00208401

Müller J, Bolte A (2009). The use of lysimeters in forest hydrology research in north-east Germany. Agriculture and Forestry Research 59: 1-10.

Nielsen ET, Orcutt DM (1998). Physiology of plants under stress: abiotic factors. John Wiley, New York, USA.

Oliveira IB, Demond AH, Salehzadeh A (1996). Packing of sands for the production of homogeneous porous media. Soil Science Society of America Journal 60 (1): 49-53. - doi: 10.2136/sssaj1996.03615995006000010010x

Oliver RJ, Finch JW, Taylor G (2009). Second generation bioenergy crops and climate change: a review of the effects of elevated atmospheric $\mathrm{CO}_{2}$ and drought on water use and the implications for yield. GCB Bioenergy 1 (2): 97-114. doi: 10.1111/j.1757-1707.2009.01011.x

Presley DR, Ransom MD, Kluitenberg GJ, and Finnell PR (2004). Effects of thirty years of irrigation on the genesis and morphology of two semiarid soils in Kansas. Soil Science Society of America Journal 68:1916-1926. - doi: 10.2136/ sssaj2004.1916

Raper SM, Steinbeck K, Moss IS, Whitehead D (1992). Water use efficiency and transpiration of Robinia, Liquidambar, and Platanus sprouts in the south eastern USA. Forest Ecology and Management 51: 259-268. - doi: 10.1016/03781127(92)90327-6

Rédei K, Veperdi I (2009). The role of black locust (Robinia pseudoacacia L.) in establishment of short-rotation energy plantations in Hungary. International Journal of Horticultural Science 15 (3): 41-44

Ritchie JT, Burnett E (1968). A precision weighing lysimeter for row crop water use studies. American Society of Agronomy 60 (5): 545-549. - doi: 10.2134/agronj1968.0002196200600005 0030x

Rodríguez-Iturbe I, Porporato A (2004). Ecohydrology of water-controlled ecosystems. University Press, Cambridge, UK.

Sinclair TR, Holdbrook NM, Zwieniecki MA (2005). Daily transpiration rates of woody species on drying soil. Tree Physiology 25: 14691472. - doi: 10.1093/treephys/25.11.1469

Smith JAC, Griffiths H (1993). Water deficits: plant responses from cell to community. Environmental Plant Biology Series, Bios Scientific Publishers, Oxford, UK, pp. 345.

Stanhill G (1986). Water use efficiency. Advances in Agronomy 39: 53-85. - doi: 10.1016/S00652113(08)60465-4

Tsakov H, Alexandrov A (2005). Growth of Robinia pseudoacacia L. on a reclaimed terrain in Bulgaria, studied over a period of climatic anomalies. Folia Oecologica 32 (1): 1-4. 
Vaughana PJ, Troutb TJ, Ayarsa JE (2007). A processing method for weighing lysimeter data and comparison to micrometeorological ETo predictions. Agricultural Water Management 88: 141-146. - doi: 10.1016/j.agwat.2006.10.008

Veste M, Böhm, C, Quinkenstein A, Freese D (2013). Biologische Stickstoff-Fixierung der Robinie. Allgemeine Forstzeitung - Der Wald 2/2013: 30-32.

Veste M, Kriebitzsch WU (2013). Einfluss von Trockenstress auf Photosynthese, Transpiration und Wachstum junger Robinien (Robinia pseudoacacia L.). Forstarchiv 84 (2).
Warrington DN, Goldstein D, Levy GJ (2007). Clay translocation within the soil profile as affected by intensive irrigation with treated wastewater. Soil Science 172 (9): 692-700. - doi: 10.1097/SS.0b013e3180d0a43d

Van Genuchten MT (1980). A closed-form equation for predicting the hydraulic conductivity of unsaturated soils. Soil Science Society of America Journal 44 (5): 892-898. - doi: 10.2136/sssaj1980.03615995004400050002x

Weihermüller L, Siemens J, Deurer M, Knoblauch S, Rupp H, Göttlein A, Pütz T (2007). In situ soil water extraction: a review. Journal of Environ- ment Quality 36: 1735-1748. - doi: 10.2134/ jeq2007.0218

Williams LE, Phene CJ, Grimes DW, Trout TJ (2003). Water use of mature Thompson Seedless grapevines in California. Irrigation Science 22: 11-18.

Zhu Y, Fox RH, Toth JD (2002). Leachate collection efficiency of zero-tension pan and passive capillary fiber wick lysimeters. Soil Science Society of America Journal 66: 37-43 - doi: 10.2136/sssaj2002.0037 